\title{
Investigation of entropy effects during sorption of mixtures of alkanes in MFI zeolite
}

\author{
R. Krishna*, S. Calero, B. Smit \\ Department of Chemical Engineering, University of Amsterdam, Nieuwe Achtergracht 166, 1018 WV Amsterdam, The Netherlands
}

Received 30 August 2001; received in revised form 15 October 2001; accepted 29 October 2001

\begin{abstract}
We have carried out a comprehensive study of sorption of mixtures of alkanes, in the 1-7 C atom range, in MFI zeolite using configurational-bias Monte Carlo (CBMC) simulations. The isotherm characteristics of various binary, ternary and quaternary mixtures have been investigated. Our studies show that two types of entropy effects have a significant influence on mixture sorption:

1. Size entropy effects arise due to differences in the saturation loading of the pure components. Size entropy effects favour the component with the smaller number of $\mathrm{C}$ atoms because the smaller molecule finds it easier to fill in the "gaps" within the zeolite matrix at high molecular loadings.

2. Configurational entropy effects come into play for mixtures of alkanes that differ in the degree of branching. For a mixture of linear and mono-methyl alkanes with the same number of $\mathrm{C}$ atoms, configurational entropy effects favour the linear isomer because such molecules "pack" more efficiently within the MFI matrix. For a mixture of mono-methyl and di-methyl alkanes with the same number of $\mathrm{C}$ atoms, configurational entropy effects favour the single branched isomer. Configurational entropy effect comes into play when the loading exceeds four molecules per unit cell, when all the intersection sites are occupied, and results in the following hierarchy of sorption strengths: linear alkanes $\gg$ mono-methyl alkanes $\gg$ di-methyl alkanes.
\end{abstract}

In all cases, the mixture isotherms can be predicted with good accuracy using the ideal adsorbed solution theory (IAST).

CBMC simulations of sorption of an 8-component mixture containing $n$-pentane $\left(n-\mathrm{C}_{5}\right)$, 2-methylbutane $(2 \mathrm{MB}), n$-hexane $\left(n-\mathrm{C}_{6}\right)$, 2-methylpentane (2MP), 2,2-dimethylbutane (22DMB), $n$-heptane $\left(n-\mathrm{C}_{7}\right), 2$-methylhexane (2MH) and 2,2-dimethylpentane (22DMP) show that both size and configurational entropy effects contribute, leading to a sorption hierarchy depending on the degree of branching, linear alkanes $\gg$ mono-methyl alkanes $\gg$ di-methyl alkanes. This result has considerable potential for commercial application in the petroleum industry in catalytic isomerization process where it is necessary to isolate the di-branched alkanes which are preferred ingredients in gasoline.

(C) 2002 Elsevier Science B.V. All rights reserved.

Keywords: Sorption; MFI zeolite; Configurational-bias Monte Carlo

\section{Introduction}

The separation of mixtures of alkanes is an important activity in the petroleum and petrochemical industries. For example, the products from a catalytic isomerization reactor consist of a mixture of linear, mono-methyl and di-methyl alkanes. Of these, the di-branched molecules are the most desired ingredients in petrol because they have the highest octane number. It is therefore required to separate the di-methyl alkanes and recycle the linear and mono-methyl alkanes back to the isomerization reactor. In the detergent

\footnotetext{
* Corresponding author. Tel.: +31-20-525-7007; fax: +31-20-525-5604. E-mail address: krishna@science.uva.nl (R. Krishna).
}

industry, the linear alkanes are the desired components and need to be separated from the alkane mixture.

Selective sorption on zeolites is often used for separation of alkane mixtures [1-7]. The choice of the zeolite depends on the specific separation task in hand. For example, small-pore Zeolite A are used for separation of linear alkanes using the molecular sieving principle; the branched molecules cannot enter the zeolite structure. Both linear and branched molecules are allowed inside the medium-pore MFI matrix and the sorption hierarchy in MFI will be dictated both by the alkane chain length and degree of branching. For the development of separation technologies we need to be able to calculate the mixture sorption characteristics for a wide range of operating conditions (pres- 


\begin{tabular}{|c|c|}
\hline \multicolumn{2}{|c|}{ Nomenclature } \\
\hline$A$ & surface area of adsorbent $\left(\mathrm{m}^{2} \mathrm{~kg}^{-1}\right)$ \\
\hline$b_{i}$ & $\begin{array}{l}\text { parameter in the Langmuir adsorption } \\
\text { isotherm }\left(\mathrm{Pa}^{-1}\right)\end{array}$ \\
\hline$k_{\mathrm{B}}$ & $\begin{array}{l}\text { Boltzmann constant } \\
\left(1.38 \times 10^{-23} \mathrm{~J}_{\text {molecule }}-1 \mathrm{~K}^{-1}\right)\end{array}$ \\
\hline$p_{i}$ & partial pressure of species $i(\mathrm{~Pa})$ \\
\hline$P$ & system pressure $(\mathrm{Pa})$ \\
\hline$P_{i}^{0}$ & vapour pressure analogue in Eq. (3) $(\mathrm{Pa})$ \\
\hline$S$ & $\begin{array}{l}\text { sorption selectivity defined by Eq. (2) } \\
\text { (dimensionless) }\end{array}$ \\
\hline$T$ & absolute temperature $(\mathrm{K})$ \\
\hline$x_{i}$ & $\begin{array}{l}\text { mole fraction of component } i \text { in the } \\
\text { adsorbed phase (dimensionless) }\end{array}$ \\
\hline$y_{i}$ & $\begin{array}{l}\text { mole fraction of component } i \text { in bulk } \\
\text { vapour phase } \\
\text { (dimensionless) }\end{array}$ \\
\hline \multicolumn{2}{|c|}{ Greek letters } \\
\hline$\Theta_{i}$ & $\begin{array}{l}\text { molecular loading (molecules per unit } \\
\text { cell or per cage) }\end{array}$ \\
\hline & $\begin{array}{l}\text { saturation loading (molecules per unit } \\
\text { cell or per cage) }\end{array}$ \\
\hline$\pi$ & spreading pressure $(\mathrm{Pa} \mathrm{m})$ \\
\hline$\rho$ & density (number of unit cells per $\mathrm{m}^{3}$ ) \\
\hline \multicolumn{2}{|c|}{ Subscripts } \\
\hline A & referring to site $\mathrm{A}$ \\
\hline B & referring to site $B$ \\
\hline & components in mixture \\
\hline & referring to mixture loading \\
\hline sat & referring to saturation conditions \\
\hline
\end{tabular}

sures, temperatures, compositions). While there are several experimental studies on pure component isotherms [8-12], there is considerably less information on mixture isotherms. The lack of mixture sorption data is most probably due to the difficulty of experimentation.

In earlier publications [13-22], we had developed the configurational-bias Monte Carlo (CBMC) simulation technique to calculate the isotherms of pure components, and binary mixtures, of alkanes in MFI zeolite. The accuracy of the CBMC simulations have been demonstrated by extensive comparison with published experimental data. The objectives of the present study are threefold. First, we extend our previous studies by performing CBMC simulations of ternary and quaternary mixtures of alkanes in MFI in order to highlight subtle size and configurational entropy effects. Second, we examine the extent to which the mixture characteristics can be predicted from information on pure component sorption behaviour using the ideal adsorbed solution theory (IAST). Finally, we show how a proper understanding, and quantification, of entropy effects can afford new separation strategies with considerable industrial potential. We restrict our attention to alkanes in the $1-7 \mathrm{C}$ atom range. We begin with a short summary of our CBMC simulation methodology.

\section{CBMC simulation methodology}

The linear and branched alkanes are described with a united-atom model, in which $\mathrm{CH}_{3}, \mathrm{CH}_{2}$, and $\mathrm{CH}$ groups are considered as single interaction centres. When these pseudo-atoms belong to different molecules or to the same molecule but separated by more than three bonds, the interaction is given by a Lennard-Jones potential. The LennardJones parameters are chosen to reproduce the vapour-liquid curve of the phase diagram as shown in Siepmann et al. [23]. The bonded interactions include bond-bending and torsion potentials. Details for the alkane model can be found in Vlugt et al. [21].

All the simulations have been performed with MFI zeolite. MFI has both, straight elliptical channels and zig-zag channels that cross at the intersections. Following Kiselev and co-workers [24], we consider the zeolite lattice to be rigid and we assume that interactions of an alkane with the zeolite are dominated by the dispersive forces between alkane pseudo-atoms and the oxygen atoms of the zeolite. These interactions are described by a Lennard-Jones potential, which parameters are given in [21].

Adsorption isotherms are conveniently computed using a Monte Carlo simulation in the grand-canonical ensemble. In this ensemble the temperature and chemical potentials are imposed. The average number of adsorbed molecules per unit cell of the zeolite follows from the simulations. The characteristics of these type of simulations is that during the calculations attempts are made to change the total number of particles by making attempts to insert molecule into or remove molecules from the zeolite. To make these types of moves possible for the long chain alkanes, we use the CBMC technique $[21,25]$. Instead of inserting a molecule at a random position, in a CBMC simulation a molecule is grown atom by atom in such a way that the "empty spots" in the zeolite are found. This growing scheme gives a bias that is removed exactly by adjusting the acceptance rules [25].

These simulations were performed in cycles and in each cycle, an attempt to perform one of the following moves was made:

1. Displacement of a randomly selected chain. The maximum displacement was adjusted to an overall acceptance of $50 \%$.

2. Rotation of a chain around its centre of mass. The chain is chosen at random and the maximum rotation angle is selected to accept $50 \%$ of the moves.

3. Partly regrowing of a chain; a chain is selected at random and part of the molecule is regrown using the CBMC scheme. It is decided at random which part of the chain is 
regrown and with which segment the regrowing is started. For branched alkanes, the approach in Vlugt et al. [21] was used.

4. Exchange with a reservoir; it is decided at random whether to add or to remove a molecule from the zeolite following the acceptance rules derived in Vlugt et al. [21].

5. Change of identity (only in the case of mixtures); one of the components is selected at random and an attempt is made to change its identity [21]. The acceptance rules for these trial moves can be found in Frenkel and Smit [25].

The number of Monte Carlo cycles performed for 1-, 2-, 3-, and 4-component isotherms were, respectively, $2 \times$ $10^{7}, 5 \times 10^{7}, 1 \times 10^{8}$ and $5 \times 10^{8}$. The relative probabilities of moves were $15 \%$ displacements, $15 \%$ rotations, $15 \%$ partial re-growths, $50 \%$ exchanges with the reservoir and the remaining $5 \%$ of the moves were attempts to change the identity of a molecule. The number of trial orientations in

(a) 1 - 4 linear alkanes

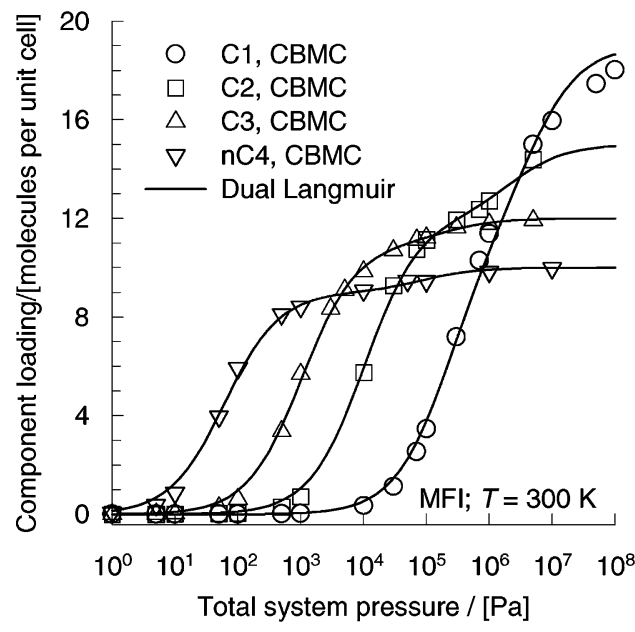

(c) 2-methylalkanes

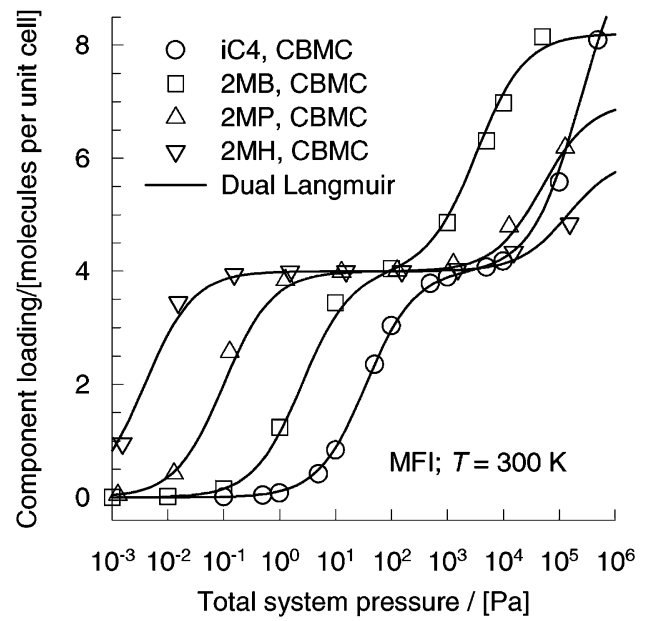

the CBMC scheme was six for all molecules. In addition, we used the multiple first bead scheme with 15 trial positions for the first bead. All simulations reported in this paper have been carried out at a temperature of $300 \mathrm{~K}$.

\section{CBMC simulation results}

\subsection{Pure component isotherms}

The sorption isotherms at $300 \mathrm{~K}$ for alkanes in MFI are shown in Fig. 1. $n$-Heptane shows a pronounced inflection at a loading of $\Theta=4$. $n$-Hexane shows a slight inflection at this loading due to "commensurate freezing" effects [26]. All 2-methyl alkanes show inflection behaviour (see Fig. 1(c)); this is because these molecules prefer to locate at the intersections between straight and zig-zag channels, which offers more "leg-room" [20,21]. At $\Theta=4$, all intersections are fully occupied. To locate the 2-methyl alkanes

(b) 5 - 7 linear alkanes

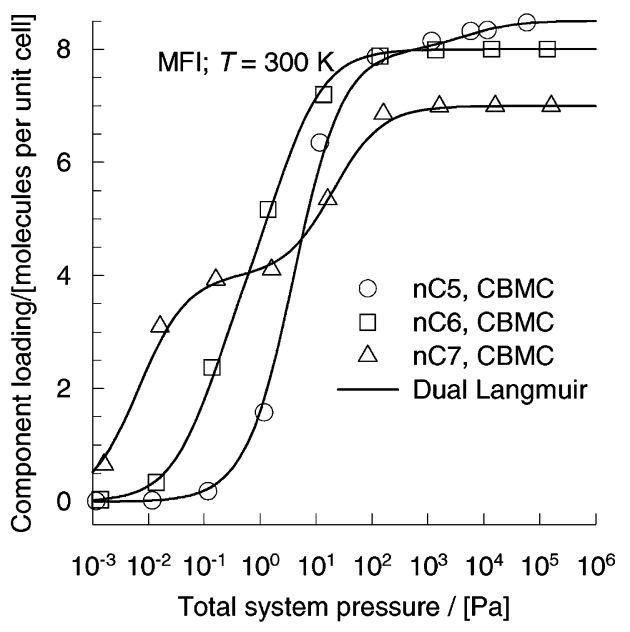

(d) di-methyl alkanes

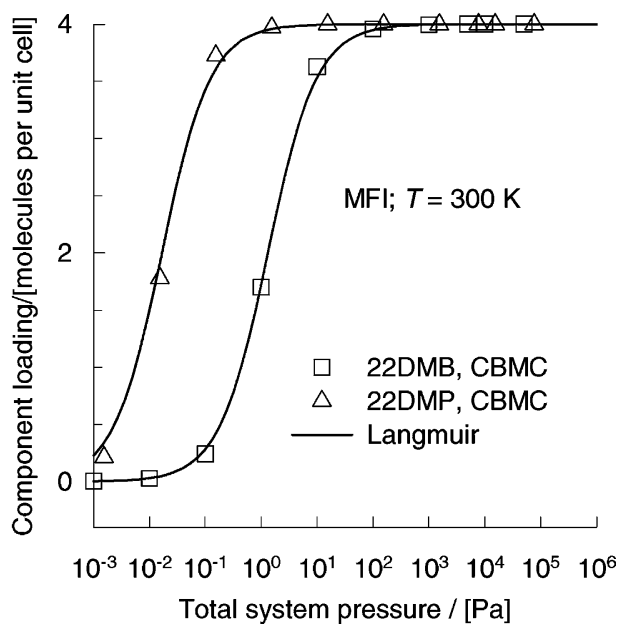

Fig. 1. Pure component isotherms for linear, 2-methyl and di-methyl alkanes in MFI calculated using CBMC simulations [21]. The continuous lines represent the fits of the isotherms using the DSL model with parameters given in Table 1. 
within the channel interiors, requires an extra push, leading to inflection behaviour. The 2,2-dimethylbutane (22DMB) and 2,2-dimethylpentane (22DMP) molecules are too bulky to be located at the channel interiors and both molecules show a maximum (saturation) loading of 4 (see Fig. 1(d)).

A good description of the pure component isotherms can be obtained with the Dual-site Langmuir (DSL) model $[1,19]$. In this model the loading, $\Theta_{i}^{0}(P)$, expressed in molecules per unit cell is expressed as a function of the pressure $P$ as follows:

$\Theta_{i}^{0}(P)=\frac{\Theta_{i, \mathrm{sat}, \mathrm{A}} b_{i, \mathrm{~A}} P}{1+b_{i, \mathrm{~A}} P}+\frac{\Theta_{i, \mathrm{sat}, \mathrm{B}} b_{i, \mathrm{~B}} P}{1+b_{i, \mathrm{~B}} P}$

The superscript 0 on $\Theta_{i}^{0}(P)$ is used to emphasize that the relation is for pure component loadings. In Eq. (1), $b_{i, \mathrm{~A}}$ and $b_{i, \mathrm{~B}}$ represent the DSL model parameters expressed in $\mathrm{Pa}^{-1}$ and the subscripts $\mathrm{A}$ and $\mathrm{B}$ refer to two sorption sites within the MFI structure, with different sorption capacities and sorption strengths. The $\Theta_{i \text {,sat,A }}$ and $\Theta_{i \text {,sat,B represent }}$ the saturation capacities of sites $\mathrm{A}$ and $\mathrm{B}$, respectively. The fitted parameters for the pure component isotherms are listed in Table 1. It is to be noted that the total saturation loading $\Theta_{i, \text { sat }}=\Theta_{i, \text { sat }, \mathrm{A}}+\Theta_{i, \text { sat }, \mathrm{B}}$ is not a fitted parameter but taken from the final plateau value of the sorption isotherm, estimated from CBMC simulations. In general, the saturation loading decreases with increasing $\mathrm{C}$ number and with increased degree of branching; see Fig. 2(a).

The Henry coefficients, calculated using the CBMC techniques (in the NVT framework), also described in earlier work [21], are shown in Fig. 2(b). On the basis of these Henry coefficients we would conclude that the hierarchy of sorption strengths roughly follows the hierarchy of $\mathrm{C}$ numbers; the higher the $\mathrm{C}$ number, the higher the adsorption strength. The Henry coefficients of linear and 2-methyl alkanes isomers are extremely close to each other and therefore we might conclude that it is not possible to separate these with high selectively. 22DMP has a higher Henry co- (a) Maximum loading

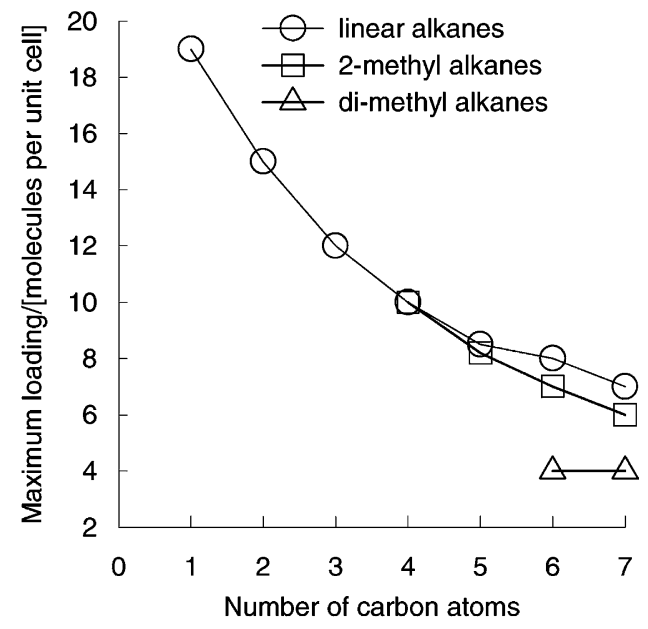

(b) Henry coefficient

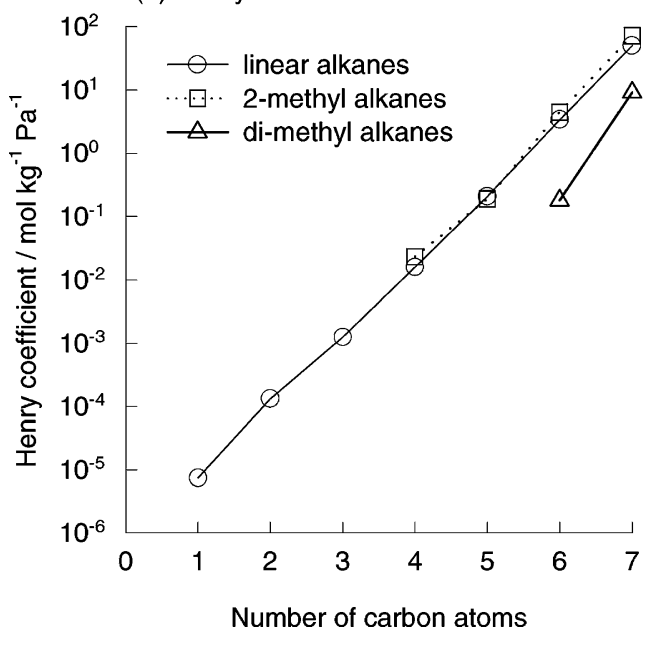

Fig. 2. (a) Maximum saturation loadings of linear and branched alkanes. (b) Henry coefficients for $n$-alkanes, 2-methyl alkanes and 2,2-dimethyl alkanes in MFI. CBMC calculations at $300 \mathrm{~K}$ using NVT simulations [21].

Table 1

DSL parameters for pure alkanes in MFI at $300 \mathrm{~K}$. The fits correspond to CBMC simulations

\begin{tabular}{|c|c|c|c|c|}
\hline \multirow[t]{3}{*}{ Component } & \multicolumn{4}{|c|}{ Dual Langmuir parameters } \\
\hline & \multicolumn{2}{|l|}{ Site A } & \multicolumn{2}{|l|}{ Site B } \\
\hline & $b_{i, \mathrm{~A}}\left(\mathrm{~Pa}^{-1}\right)$ & $\Theta_{i, \text { sat }, \mathrm{A}}($ molecules per unit cell) & $b_{i, \mathrm{~B}}\left(\mathrm{~Pa}^{-1}\right)$ & $\Theta_{i, \text { sat }, \mathrm{B}}$ (molecules per unit cell) \\
\hline $\mathrm{C}_{1}$ & $4.86 \times 10^{-6}$ & 11.0 & $2.38 \times 10^{-7}$ & 8.0 \\
\hline $\mathrm{C}_{2}$ & $9.73 \times 10^{-5}$ & 12.0 & $4.38 \times 10^{-7}$ & 3.0 \\
\hline $\mathrm{C}_{3}$ & $9.64 \times 10^{-4}$ & 11.0 & $5.06 \times 10^{-6}$ & 1.0 \\
\hline$n-\mathrm{C}_{4}$ & $1.63 \times 10^{-2}$ & 9.0 & $1.14 \times 10^{-5}$ & 1.0 \\
\hline$n-\mathrm{C}_{5}$ & 0.25 & 8.0 & $2 \times 10^{-4}$ & 0.5 \\
\hline $2 \mathrm{MB}$ & 0.4 & 4.0 & $3 \times 10^{-4}$ & 4.2 \\
\hline$n-\mathrm{C}_{6}$ & 7.0 & 4.0 & 0.4 & 4.0 \\
\hline 2MP & 10.0 & 4.0 & $2.0 \times 10^{-5}$ & 3.0 \\
\hline 22DMB & 0.76 & 4.0 & - & 0 \\
\hline$n-\mathrm{C}_{7}$ & 150 & 4.0 & $5 \times 10^{-2}$ & 3.0 \\
\hline $2 \mathrm{MH}$ & 260 & 4.0 & $7 \times 10^{-6}$ & 2.0 \\
\hline 22DMP & 60 & 4.0 & - & 0 \\
\hline
\end{tabular}


efficient than the $\mathrm{C}_{6}$ isomers while 22DMB has a higher Henry coefficient than the $\mathrm{C}_{5}$ isomers. For a mixture of 5-7 alkanes, we might conclude that it is not possible to separate the di-methyl alkanes selectively because of "interference" between chain length and branching considerations. We aim to show in the following that the above conclusions regarding separation possibilities reached on the basis of the Henry coefficients can be completely misleading.

\subsection{Sorption of mixtures of linear alkanes in the $1-4 C$ atom range}

Let us first consider an equimolar (50-50) mixture of $\mathrm{C}_{3}$ and $n-\mathrm{C}_{4}$. The component loadings obtained using CBMC simulations are shown in Fig. 3(a). The loading of $\mathrm{C}_{3}$ continually increases with increasing pressure. On the other hand, the loading of $n-\mathrm{C}_{4}$ reaches a plateau value for pressures in the $10-100 \mathrm{kPa}$ range. Increasing the total systems

(a) 50-50 mixture isotherm

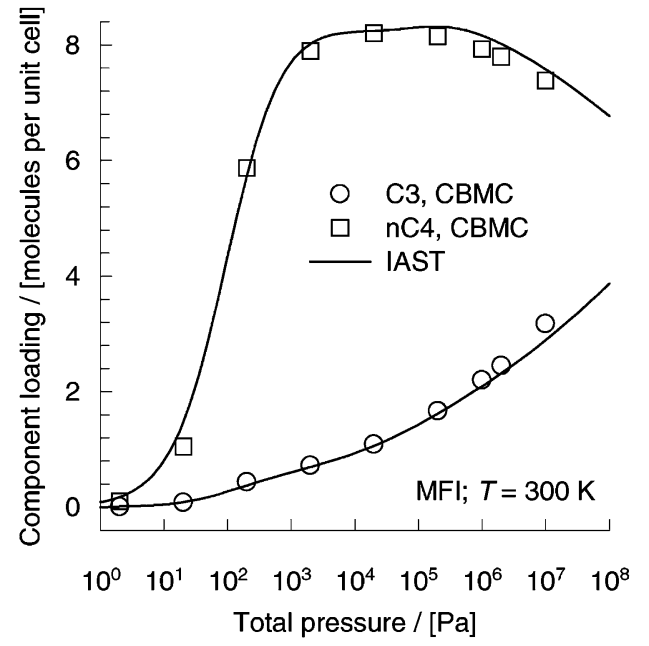

(c) 95-5 mixture isotherm

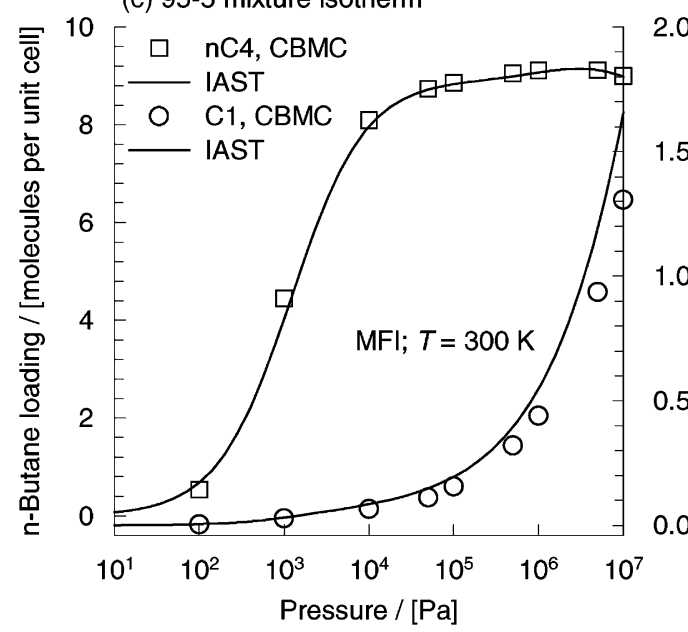

pressure beyond $100 \mathrm{kPa}$, leads to a decline in the loading of $n-\mathrm{C}_{4}$. In Fig. 3(b) we plot the sorption selectivity, $S_{1,2}$, defined by:

$S_{1,2}=\frac{\Theta_{1} / \Theta_{2}}{p_{1} / p_{2}}$

where $p_{1}$ and $p_{2}$ are the partial pressures in the bulk gas phase; for an equimolar mixture, $p_{1}=p_{2}$. For mixture loadings, $\Theta_{\text {mix }}=\Theta_{1}+\Theta_{2}$, below 8, the sorption selectivity of $n-\mathrm{C}_{4}$ with respect to $\mathrm{C}_{3}$ is practically constant and equals that calculated from the corresponding Henry coefficients shown in Fig. 2(b), i.e. 13. However, as $\Theta_{\text {mix }}$ increases beyond 8 , the sorption selectivity decreases dramatically to values just above unity. Near-saturation loadings, the vacant spaces in the zeolite are more easily occupied by the smaller propane molecule. This is a size entropy effect that favours smaller sized molecules. It is clear that the size entropy effects counters the effect of chain length; in-
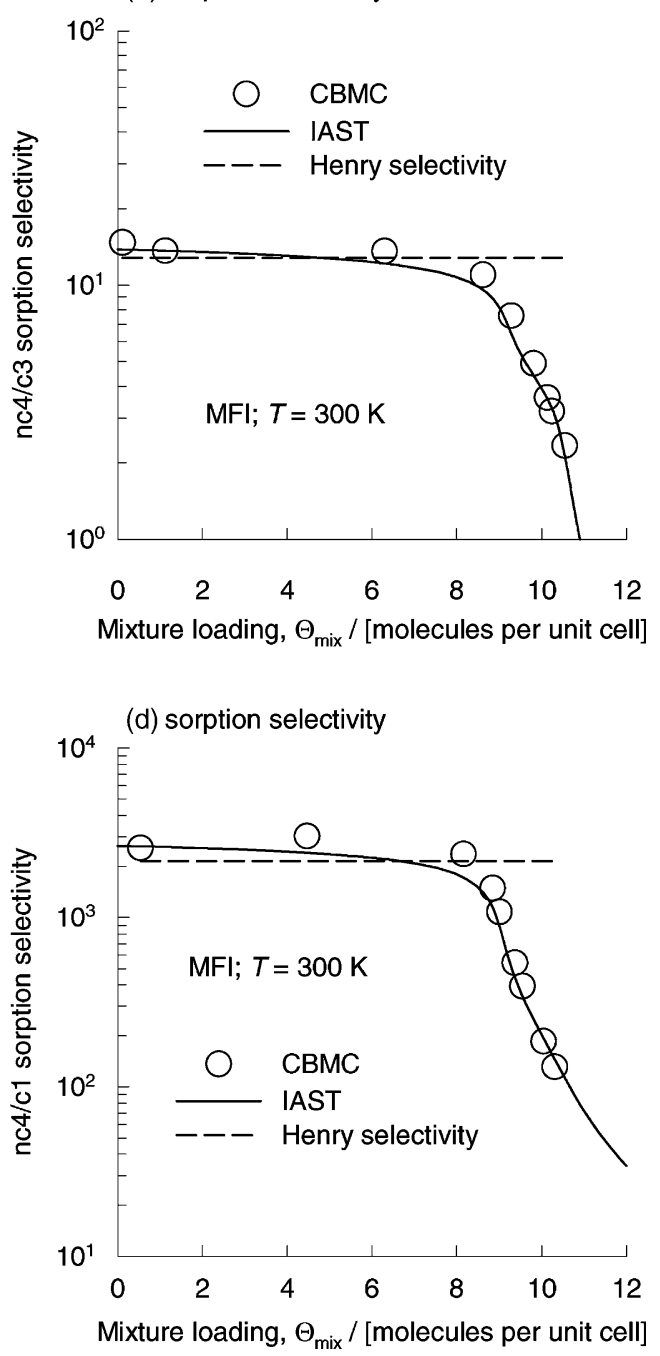

Fig. 3. (a) Sorption loadings of equimolar binary mixture of $\mathrm{C}_{3}$ and $n$-C $\mathrm{C}_{4}$. (b) $n-\mathrm{C}_{4} / \mathrm{C}_{3}$ sorption selectivity. (c) Sorption loadings of $95-5$ binary mixture of $\mathrm{C}_{1}$ and $n-\mathrm{C}_{4}$. (d) $n-\mathrm{C}_{4} / \mathrm{C}_{1}$ sorption selectivity. The continuous lines represent the predictions of the IAST. 
crease in the chain length favours sorption of the larger sized molecule.

From a practical point of view it is important to be able to predict the mixture isotherms from pure component isotherm data. It is clear that the multicomponent Langmuir isotherm will be totally unsuccessful in this regard because the sorption selectivity predicted by this model will be independent of the mixture loading. We try to estimate the mixture loadings from the pure component isotherms using the IAST of Myers and Prausnitz [27]. Briefly, the basic equation of IAST theory is the analogue of Raoult's law for vapour-liquid equilibrium, i.e.

$P y_{i}=P_{i}^{0}(\pi) x_{i}, \quad i=1,2, \ldots, n$

where $x_{i}$ is the mole fraction in the adsorbed phase

$x_{i}=\frac{\Theta_{i}}{\Theta_{1}+\Theta_{2}+\cdots+\Theta_{n}}$

and $P_{i}^{0}(\pi)$ is the pressure for sorption of every pure component $i$, which yields the same spreading pressure, $\pi$, as that for the mixture. The spreading pressure is defined by the Gibbs adsorption isotherm

$\frac{\pi A}{k_{\mathrm{B}} T}=\rho \int_{P=0}^{P=P_{i}^{0}} \frac{\Theta_{i}^{0}(P)}{P} \mathrm{~d} P$

where $A$ is the surface area per $\mathrm{m}^{3}$ of the adsorbent, $k_{\mathrm{B}}$ the Boltzmann constant, $\rho$ the density of MFI expressed in terms of the number of unit cells per $\mathrm{m}^{3}$ and $\Theta_{i}^{0}(P)$ the pure component isotherm given by Eq. (1). The total amount adsorbed is obtained from

$$
\begin{aligned}
\Theta_{\text {mix }} & \equiv \Theta_{1}+\Theta_{2}+\cdots+\Theta_{n} \\
& =\frac{1}{x_{1} / \Theta_{1}^{0}\left(P_{1}^{0}\right)+x_{2} / \Theta_{2}^{0}\left(P_{2}^{0}\right)+\cdots+x_{n} / \Theta_{n}^{0}\left(P_{n}^{0}\right)}
\end{aligned}
$$

The set of Eqs. (1), (3)-(6) need to be solved numerically to obtain the loadings of the individual components in the mixture.

We see in Fig. 3(a) and (b) that the IAST predictions are in excellent agreement with the CBMC simulation results. Size entropy effects are properly accounted for in the IAST mixture model.

Consider a 95-5 mixture of $\mathrm{C}_{1}$ and $n-\mathrm{C}_{4}$. The component loadings in the mixture obtained from CBMC simulations are shown in Fig. 3(c). For high mixture loadings, size entropy effects favour the smaller methane molecule and such effects are much stronger than in the foregoing case for the $\mathrm{C}_{3} / n-\mathrm{C}_{4}$ mixture. We note that the separation selectivity decreases from 2000, at low loadings, to about 20 as saturation loadings are approached. Both component loadings and the sorption selectivity are very well predicted by the IAST.

Consider an equimolar quaternary mixture of $\mathrm{C}_{1}, \mathrm{C}_{2}, \mathrm{C}_{3}$ and $n-\mathrm{C}_{4}$. Size entropy effects benefit the smaller molecules in a hierarchical manner. $n$-Butane bears the brunt of this effect and the $n-\mathrm{C}_{4} / n-\mathrm{C}_{1}$ selectivity decreases to values even lower than in the 95-5 binary mixture with $\mathrm{C}_{1}$; compare (a) equimolar quaternary mixture

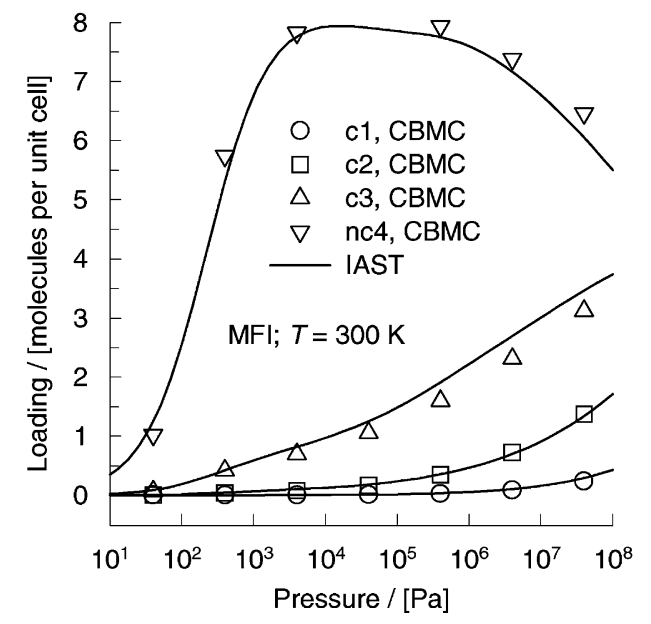

(b) selectivity in equimolar quaternary mixture

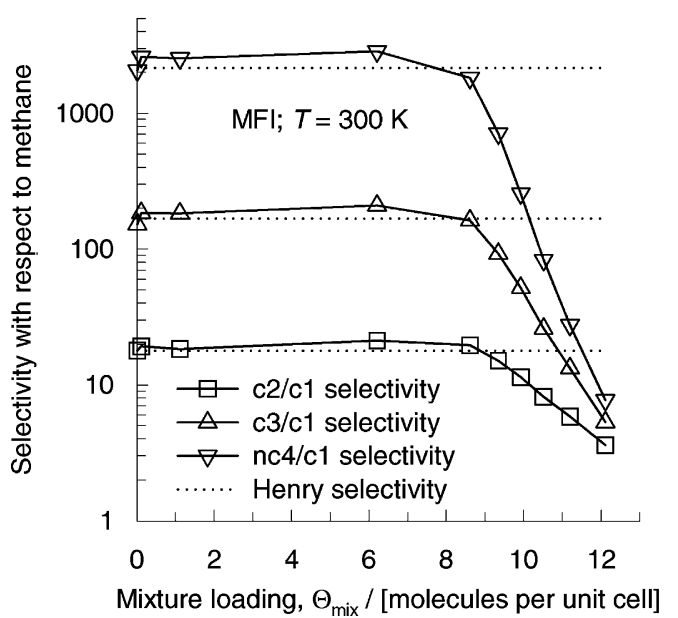

Fig. 4. (a) Sorption loadings of equimolar quaternary mixture of $\mathrm{C}_{1}, \mathrm{C}_{2}$, $\mathrm{C}_{3}$ and $n-\mathrm{C}_{4}$. (b) Sorption selectivities with respect to $\mathrm{C}_{1}$. The continuous lines in (a) represent the predictions of the IAST.

Figs. 3(d) and 4(b). This is because $n$ - $\mathrm{C}_{4}$ loses the size entropy battle with $\mathrm{C}_{1}, \mathrm{C}_{2}$ and $\mathrm{C}_{3}$ in the quaternary mixture. The IAST predicts the loadings in the quaternary mixture with very good accuracy.

MFI membrane permeation data in published literature $[28,29]$ provides confirmation of the importance of size entropy effects and underlines the need for using the IAST for predicting the mixture isotherms.

\subsection{Sorption of equimolar binary mixtures of alkanes in the 5-7 $C$ atom range}

Fig. 5(a)-(c) show the CBMC simulations for $n-\mathrm{C}_{5}-2 \mathrm{MB}$, $n-\mathrm{C}_{6}-2 \mathrm{MP}$ and $n-\mathrm{C}_{7}-2 \mathrm{MH}$ mixtures. For $\Theta_{\text {mix }}<4$, the isomers have practically the same sorption strength. However, for all the three isomeric mixtures, the loading of the mono-branched isomer reduces to very low values when $\Theta_{\text {mix }}>4$. The reason for this "exclusion" of the 2-methyl 
(a) $\mathrm{nC} 5$ - 2MB equimolar mixture

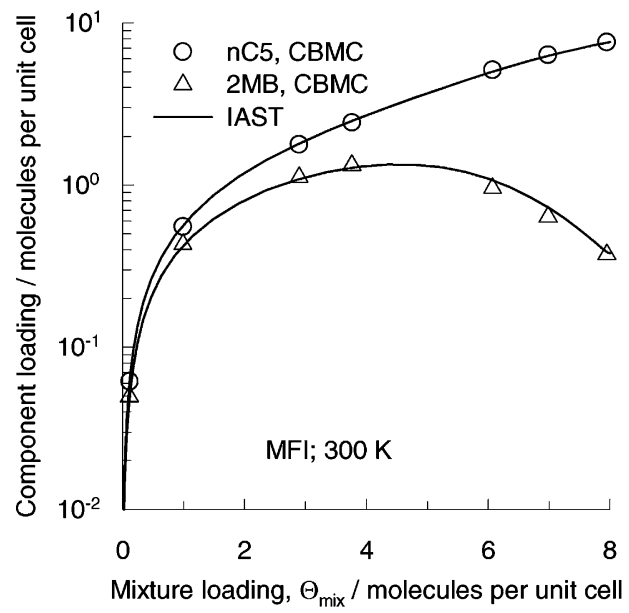

(c) $\mathrm{nC} 7-2 \mathrm{MH}$ equimolar mixture

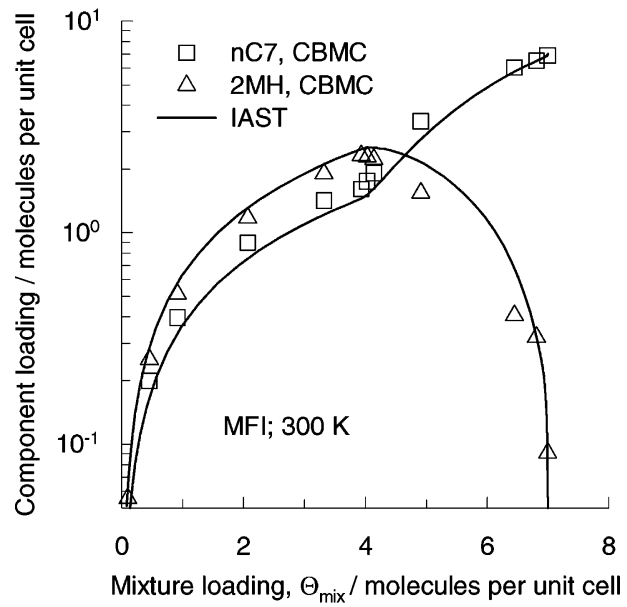

(e) nC5 - nC6 equimolar mixture

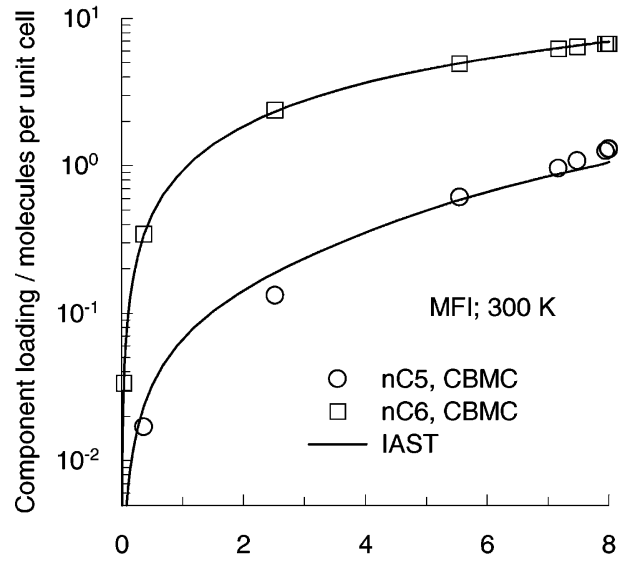

Mixture loading, $\Theta_{\text {mix }} /$ molecules per unit cell (b) $\mathrm{nC6}$ - 2MP equimolar mixture

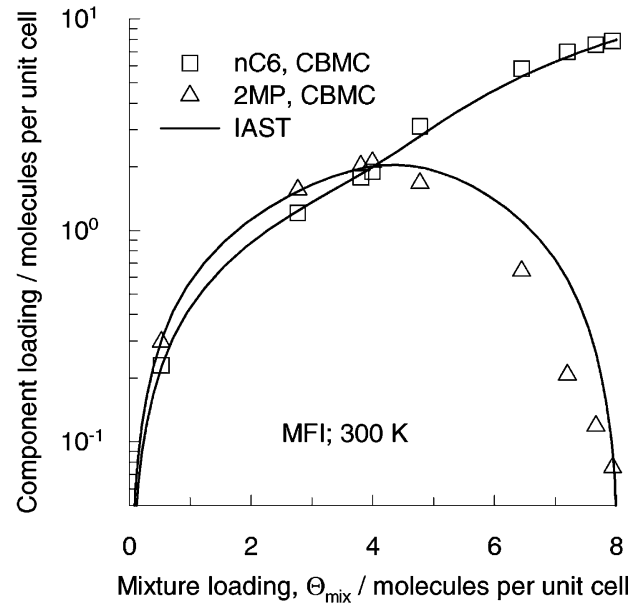

(d) 2MH - 22DMP equimolar mixture

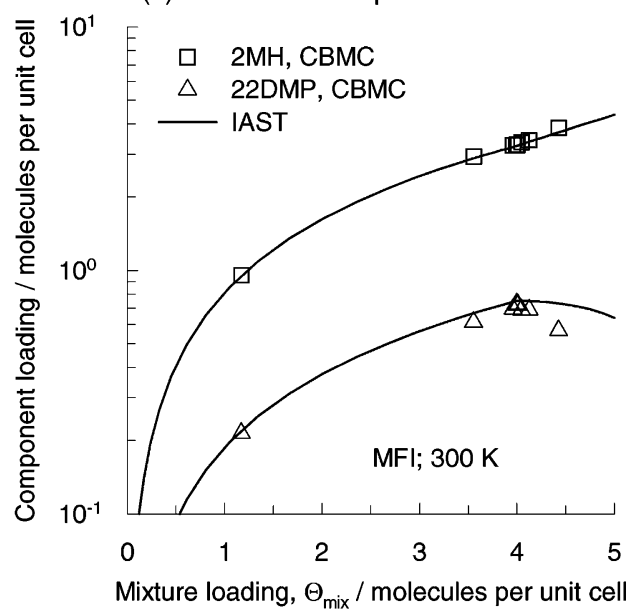

(f) nC5 - 2MP equimolar mixture

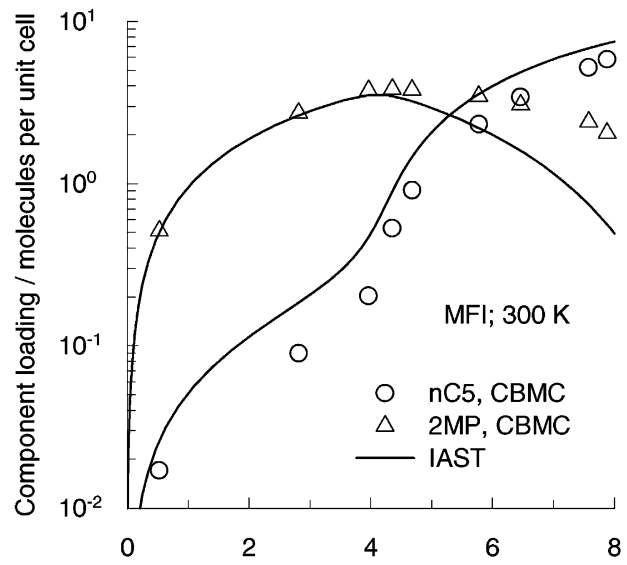

Mixture loading, $\Theta_{\text {mix }} /$ molecules per unit cell

Fig. 5. Sorption loadings of various equimolar binary mixtures in the 5-7 C atom range in MFI. The continuous lines represent the predictions of the IAST. 
alkanes is because of configurational entropy effects which tends to favour the linear isomer. For $\Theta_{\text {mix }}<4$, the 2-methyl alkanes prefer to locate at the intersections between the straight channels and zig-zag channels [20,21]. The normal alkanes can be located anywhere within the MFI matrix. At $\Theta_{\text {mix }}=4$, all the intersection sites are fully occupied. All 2-methyl alkanes demand an extra "push" to locate within the channel interiors (witness the inflection in the pure component isotherms in Fig. 1(c)). The 2-methyl alkanes suffer a penalty from configurational entropy considerations because these molecules "pack" less efficiently within the MFI matrix. This configurational entropy penalty causes the 2-methyl alkanes to be virtually excluded from the MFI matrix near-saturation loadings $\Theta_{\text {mix }}=8$.

Published data on MFI membrane permeation confirms the possibility of separating linear and mono-branched alkanes at high selectivities provided the total mixture loading is in excess of 4 [18-20,30-32].

For a binary mixture of mono-branched and di-branched alkanes, configurational entropy effects tends to favour the mono-branched alkane. This is evidenced in Fig. 5(d) that gives the sorption loadings for a binary mixture of $2 \mathrm{MH}$ and 22DMP. For $\Theta_{\text {mix }}>4$, the $2 \mathrm{MH}$ loading increases at the expense of 22DMP.

For a mixture of two linear alkanes the sorption loadings are primarily dictated by chain length considerations; the molecules with the longer chain length has a higher sorption strength; this is illustrated in Fig. 5(e) for $n-\mathrm{C}_{5}-n-\mathrm{C}_{6}$ mixture. Size entropy effects favours $n-\mathrm{C}_{5}$ but this effect is less strong than evidenced for mixtures of $\mathrm{C}_{1}, \mathrm{C}_{2}, \mathrm{C}_{3}$ and $n$ - $\mathrm{C}_{4}$ alkanes; the difference in the saturation loadings of $n-\mathrm{C}_{5}$ and $n$ - $\mathrm{C}_{6}$ is very small, 8.5 vs. 8 molecules per unit cell.

The sorption behaviour of a mixture of $n-\mathrm{C}_{5}-2 \mathrm{MP}$ is less intuitively obvious; the CBMC simulation results are shown in Fig. 5(f). At $\Theta_{\text {mix }} \ll 4$, 2MP sorption is favoured because of the chain length consideration. However, when $\Theta_{\text {mix }}=4$, all the intersection sites are fully occupied and the 2MP molecules demand an extra push to locate within the channel interiors. On the other hand, the $n-\mathrm{C}_{5}$ molecules can be easily located everywhere within the MFI matrix. For $\Theta_{\text {mix }}>4$, configurational entropy effects override the chain length considerations and the $n-\mathrm{C}_{5}$ loading exceeds that of 2MP. This selectivity reversal is important from a practical point of view and this effect would also be realized for $n-\mathrm{C}_{6}-2 \mathrm{MH}$ mixtures.

Also shown in Fig. 5 are the IAST calculations of the component loadings; these are in good agreement with the CBMC simulation results; it appears that the IAST mixture rule properly accounts for both size and configurational entropy effects.

\subsection{Sorption of equimolar ternary mixtures of $C_{5}-C_{7}$ alkanes}

CBMC simulations of the component loadings for an equimolar ternary mixture of $n-\mathrm{C}_{5}-n-\mathrm{C}_{6}-n-\mathrm{C}_{7}$ are shown in
Fig. 6(a). For $\Theta_{\text {mix }}<4$, the sorption hierarchy is dictated by the $\mathrm{C}$ number, i.e. $n-\mathrm{C}_{7}>n-\mathrm{C}_{6}>n-\mathrm{C}_{5}$. With increasing $\Theta_{\text {mix }}$ both chain length considerations and entropy effects come into action. The $n-\mathrm{C}_{7} / n-\mathrm{C}_{6}$ selectivity decreases from 15 to values below unity because of both size and configurational entropy effects which favour $n-\mathrm{C}_{6}$; this is because $n-\mathrm{C}_{7}$ exhibits stronger inflection behaviour (see Fig. 1(b)). The $n-\mathrm{C}_{6} / n-\mathrm{C}_{5}$ selectivity decreases because of similar reasons. Near-saturation loadings $\left(\Theta_{\operatorname{mix}} \approx 8\right)$ the sorption hierarchy is $n-\mathrm{C}_{6} \approx n-\mathrm{C}_{7}>n-\mathrm{C}_{5}$.

Now consider a mixture of 2-methyl alkanes. CBMC simulations carried out for an equimolar mixture of $2 \mathrm{MB}$, 2MP and 2MH are shown in Fig. 6(b). All three molecules prefer to locate at the intersections. At $\Theta_{\text {mix }}=4$, all the intersections are fully occupied. In order to locate the mono-branched molecules within the channel interiors an extra push is required; this push is highest for $2 \mathrm{MH}$, and decreases for $2 \mathrm{MP}$; see the pure component isotherms in Fig. 1(c). The 2MB molecules exhibit only a slight inflection (see Fig. 1(c)) and these molecules do not demand too much extra effort (i.e. pressure) to locate within the channel interiors. As a consequence, the 2MB component loading increases sharply when the mixture loading exceeds 4 (cf. Fig. 6(b)). At saturation mixture loadings $\left(\Theta_{\text {mix }} \approx 8\right)$ it is interesting to note that the $2 \mathrm{MB}$ loadings exceeds that of 2MP and almost equals that of $2 \mathrm{MH}$. The CBMC simulation results in Fig. 6(b) underline the strong configurational entropy effects that tend to override chain length considerations for a mixture of 2-methyl alkanes.

CBMC simulations for an equimolar mixture of $n-\mathrm{C}_{5}$, $n-\mathrm{C}_{6}$ and 2MP are shown in Fig. 6(c). The loadings of the three components follow a "normal" behaviour for $\Theta_{\text {mix }}<$ 2 and the sorption loadings follow the hierarchy dictated by the Henry coefficients. When $\Theta_{\text {mix }}=4$ molecules per unit cell, all the intersection sites are occupied and from this point onward configurational entropy effects come into play. The 2MP loading shows a maximum at a mixture loading of 4 and decreases significantly when $\Theta_{\text {mix }}$ is increased. Configurational entropy effects serve to exclude the branched isomer from the MFI matrix; it is more efficient to pack the zeolite with the two linear alkanes. When $\Theta_{\text {mix }}>6$, the $n-\mathrm{C}_{5}$ loading exceeds that of 2MP, demonstrating that configurational entropy effects dominate chain length considerations. The CBMC simulations show that for this mixture, it is possible to separate both the linear alkanes from 2MP with high selectivity. For all ternary mixtures, the predictions of the component loadings from IAST are in good accord with CBMC simulations.

\subsection{Sorption of equimolar quaternary mixtures of $\mathrm{C}_{5}-\mathrm{C}_{7}$ alkanes}

Consider an equimolar quaternary mixture of $n-\mathrm{C}_{5}, n-\mathrm{C}_{6}$, 2MB and 2MP. The CBMC simulations in Fig. 7(a) show that both mono-branched alkanes exhibit a maximum in their loadings when $\Theta_{\text {mix }}=4$. When $\Theta_{\text {mix }}$ is increased 
(a) $\mathrm{nC} 5-\mathrm{nC} 6-\mathrm{nC} 7$ equimolar mixture

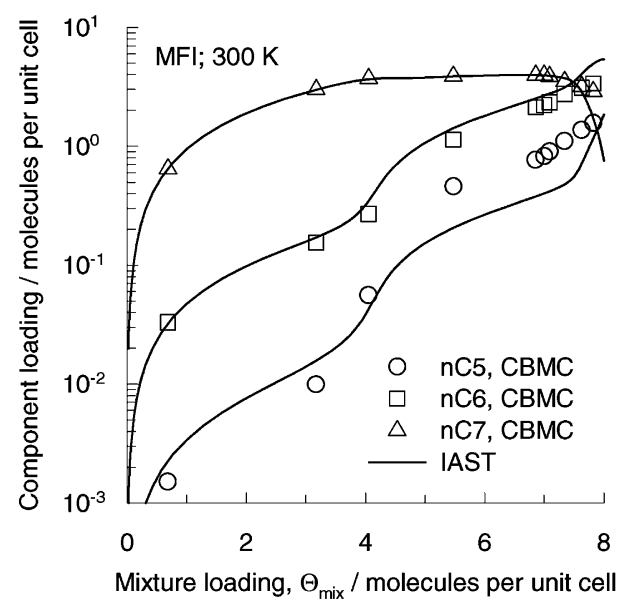

(b) 2MB - 2MP - 2MH equimolar mixture

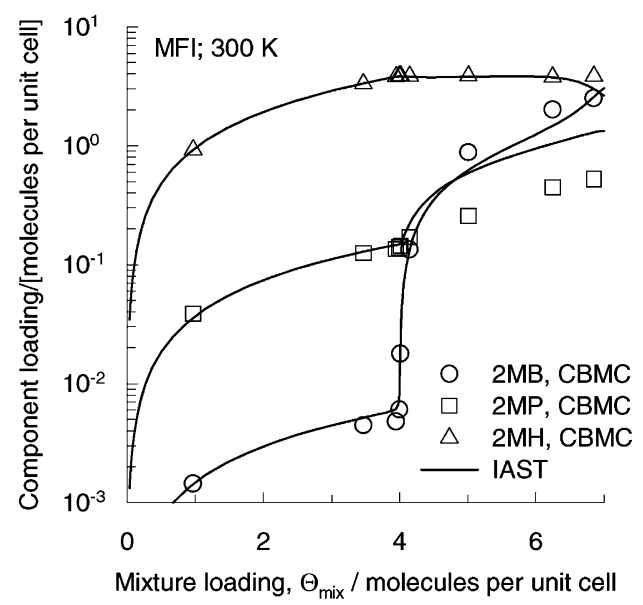

(c) nC5 - nC6 - 2MP equimolar mixture

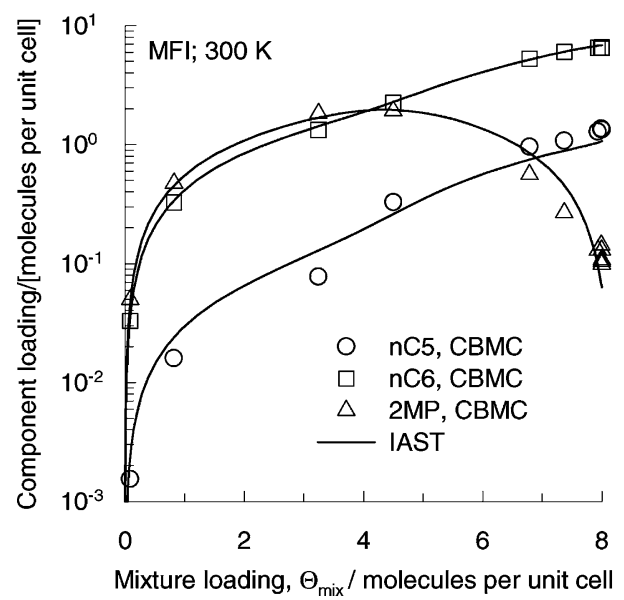

Fig. 6. Sorption loadings of various equimolar ternary mixtures in the 5-7 C atom range in MFI. The continuous lines represent the predictions of the IAST. to near-saturation (i.e. $\Theta_{\text {mix }} \approx 8$ ), the sorption hierarchy is $n-\mathrm{C}_{6} \gg n-\mathrm{C}_{5} \gg 2 \mathrm{MP} \gg 2 \mathrm{MB}$. An exactly analogous result is obtained for the quaternary mixture of $n-\mathrm{C}_{5}, n-\mathrm{C}_{7}$, $2 \mathrm{MB}$ and $2 \mathrm{MH}$; see Fig. 7(b). In this case at near-saturation loadings the sorption hierarchy is $n-\mathrm{C}_{7}>n-\mathrm{C}_{5} \gg 2 \mathrm{MH} \gg$ $2 \mathrm{MB}$. It is remarkable to note that at saturation the sorption strength of $n-\mathrm{C}_{5}$ exceeds that of $2 \mathrm{MH}$ even though its Henry coefficient is about 350 times smaller; cf. Fig. 2(b). The results of Fig. 7(a) and (b) allow us to conclude that linear alkanes can be separated from mono-branched alkanes with high selectivities at near-saturation loadings using MFI.

Consider the quaternary mixture of mono- and di-branched alkanes: 2MB, 2MP, $2 \mathrm{MH}$ and 22DMP. CBMC simulations of the component loadings are shown in Fig. 7(c). The di-branched 22DMP suffers most from configurational entropy effects; note the maximum in the 22DMP loading when $\Theta_{\text {mix }}=4$. The smallest molecule, $2 \mathrm{MB}$, is the benefactor from entropy considerations; its loading shows a sharp increase when the $\Theta_{\text {mix }}>4$ because all other molecules in the mixture need significant pushes to locate within the channel interiors. At saturation (i.e. $\Theta_{\text {mix }} \approx 8$ ), the sorption hierarchy is $2 \mathrm{MH} \approx 2 \mathrm{MB}>2 \mathrm{MP}>22 \mathrm{DMP}$ and the di-branched 22DMP is practically excluded from the MFI matrix. An exactly analogous result is obtained for the quaternary mixture $2 \mathrm{MB}, 2 \mathrm{MP}, 2 \mathrm{MH}$ and $22 \mathrm{DMB}$; see Fig. 7(d). In this case, 22DMB is practically excluded from the MFI matrix for saturation loadings. For the quaternary mixture $2 \mathrm{MP}, 2 \mathrm{MH}, 22 \mathrm{DMB}$ and $22 \mathrm{DMP}$ both the di-branched alkanes exhibit maxima in the component loadings when $\Theta_{\text {mix }}=4$; see Fig. 7(e). At saturation, both the di-branched alkanes 22DMB and 22DMP are virtually excluded from the MFI matrix. The CBMC simulation results shown in Fig. 7(c)-(e) allow us to conclude that mono-branched alkanes can be separated from di-branched alkanes with high selectivities at near-saturation loadings (i.e. $\Theta_{\text {mix }} \approx 8$ ).

Finally, we consider the quaternary mixture $n-\mathrm{C}_{5}, 2 \mathrm{MB}$, 2MP and 22DMP for which the CBMC simulation results for the component loadings are shown in Fig. 7(f). Both 2MP and 22DMP exhibit maxima in the component loading when $\Theta_{\text {mix }}=4$. The loading of the mono-branched 2MB remains practically constant for $\Theta_{\text {mix }}>4$ and only the linear $n-\mathrm{C}_{5}$ molecule increases in loading. At saturation (i.e. $\Theta_{\text {mix }} \approx 8$ ) the hierarchy of sorption loadings is $n-\mathrm{C}_{5}>$ $2 \mathrm{MP}>2 \mathrm{MB}>22 \mathrm{DMP}$, showing that it is possible to separate linear, mono-branched and di-branched alkanes at high selectivities. For all the quaternary mixtures studied, the predictions of the IAST are in good accord with the CBMC simulation results.

\subsection{Sorption of equimolar 8-component mixture of $\mathrm{C}_{5}-\mathrm{C}_{7}$ alkanes}

In the catalytic isomerization process, we have the problem of separating a mixture of linear, mono-branched and di-branched alkanes in the 5-7 $\mathrm{C}$ atom range. In the 
(a) $\mathrm{nC5}$ - nC6 - 2MB - 2MP equimolar mixture

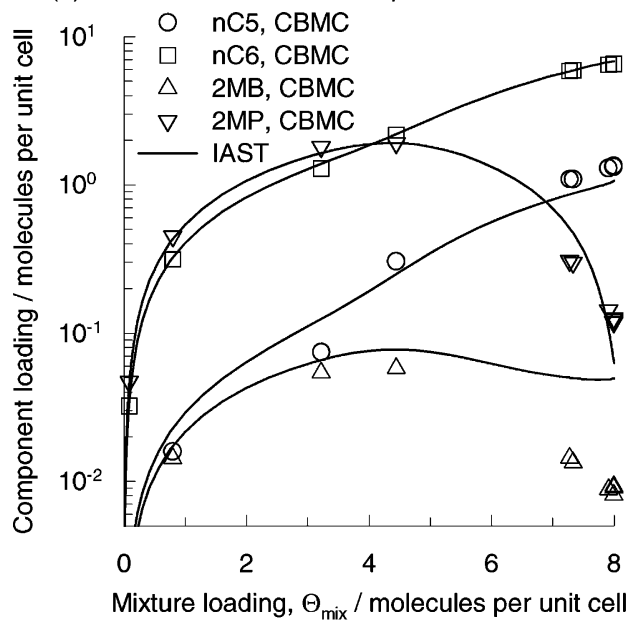

(c) $2 \mathrm{MB}-2 \mathrm{MP}-2 \mathrm{MH}-22 \mathrm{DMP}$ equimolar mixture

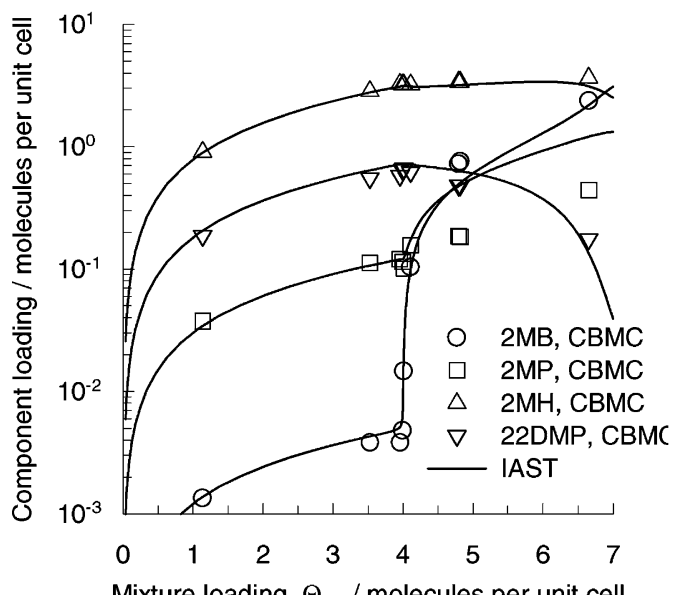

Mixture loading, $\Theta_{\text {mix }} /$ molecules per unit cell

(e) 2MP - 22DMB - 2MH - 22DMP equimolar mixture

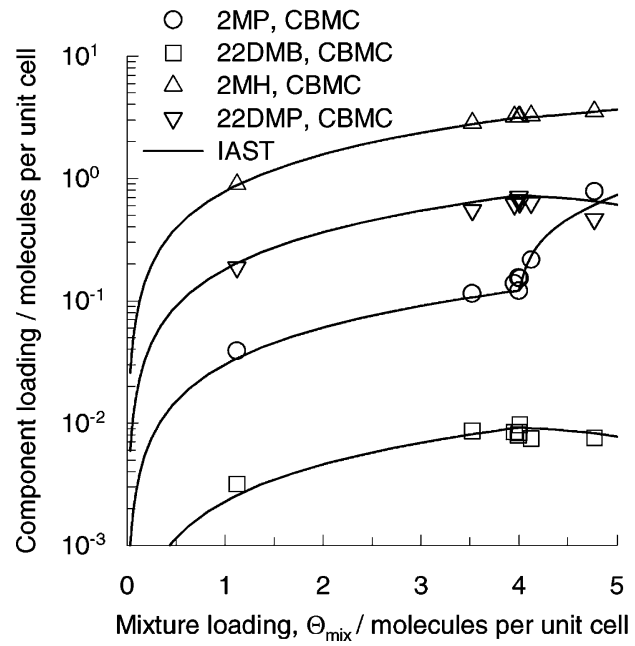

(b) $\mathrm{nC5}-2 \mathrm{MB}-\mathrm{nC7}-2 \mathrm{MH}$ equimolar mixture

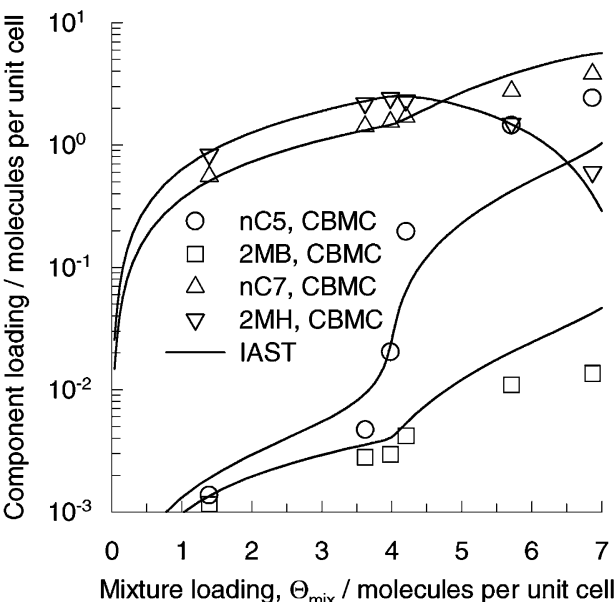

(d) $2 \mathrm{MB}-2 \mathrm{MP}-22 \mathrm{DMB}-2 \mathrm{MH}$ equimolar mixture

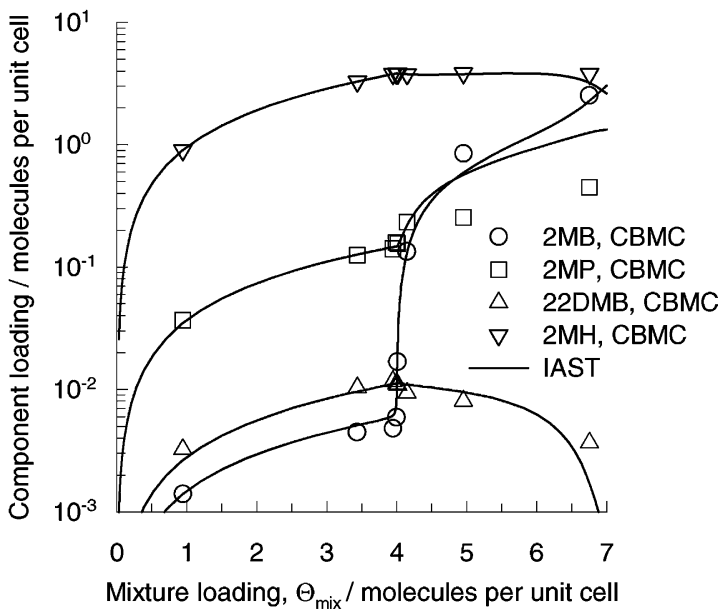

(f) $\mathrm{nC5}$ - 2MB - 2MP - 22DMB equimolar mixture

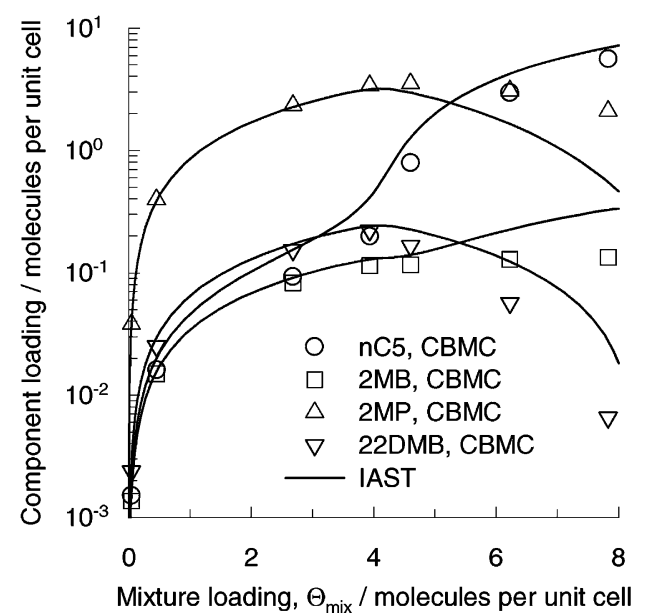

Fig. 7. Sorption loadings of various equimolar quaternary mixtures in the 5-7 C atom range in MFI. The continuous lines represent the predictions of the IAST. 
(a) component loadings vs pressure

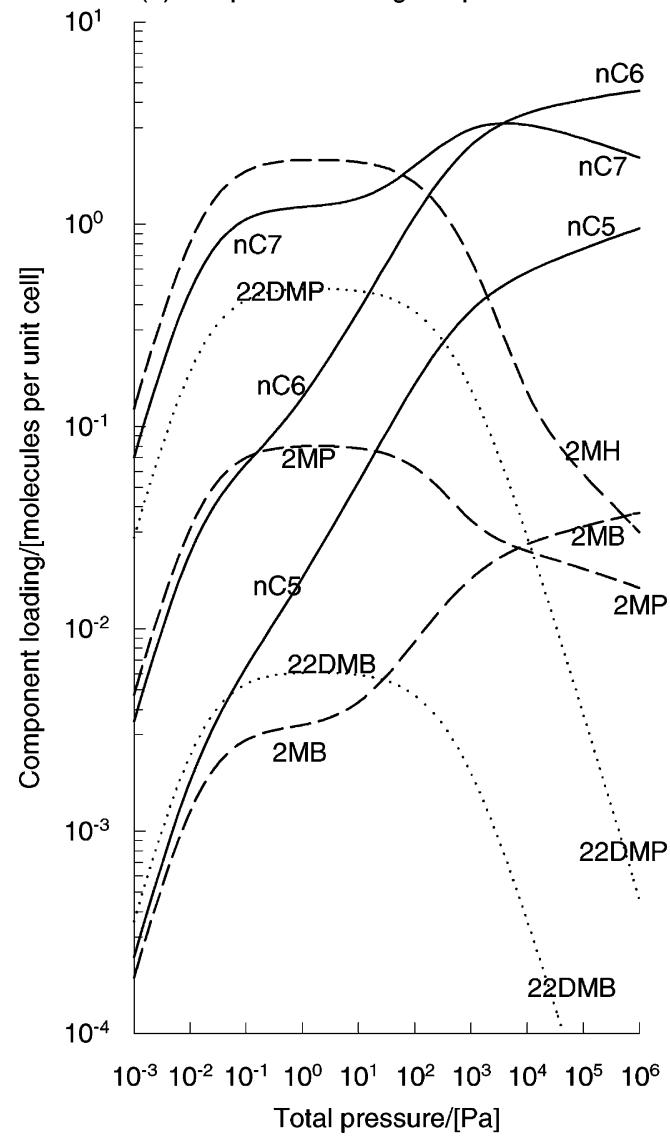

(b) component loadings vs total loading

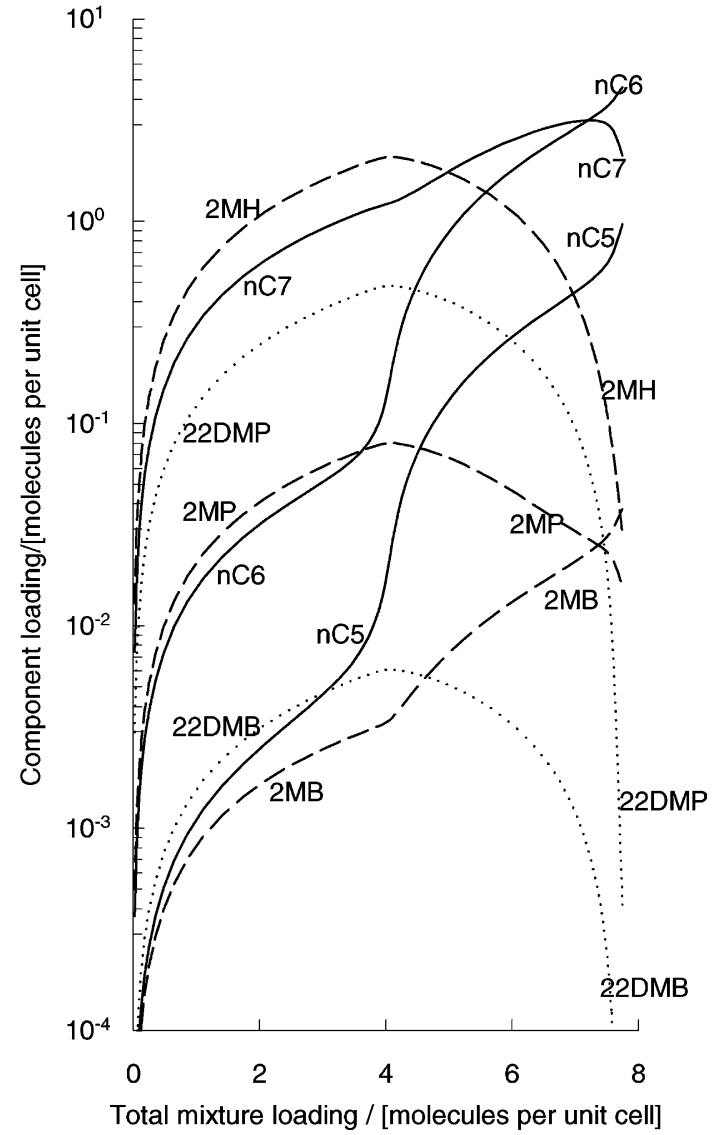

Fig. 8. (a) Component loadings in an equimolar 8-component mixture $n-\mathrm{C}_{5}-2 \mathrm{MB}-n-\mathrm{C}_{6}-2 \mathrm{MP}-22 \mathrm{DMB}-n-\mathrm{C}_{7}-2 \mathrm{MH}-22 \mathrm{DMP}$ at $300 \mathrm{~K}$ in MFI as a function of total system pressure. (b) Component loadings as a function of total mixture loading $\Theta_{\text {mix }}$. Predictions of the IAST on the basis of the pure component isotherm data given in Table 1.

foregoing discussions, we have underlined the capability of the IAST model to predict component loadings in binary, ternary and quaternary mixtures with good accuracy. We now use the IAST model to calculate the component loadings in the equimolar 8-component mixture $n$ - $\mathrm{C}_{5}-2 \mathrm{MB}-n-\mathrm{C}_{6}-2 \mathrm{MP}-22 \mathrm{DMB}-n-\mathrm{C}_{7}-2 \mathrm{MH}-22 \mathrm{DMP}$ at $300 \mathrm{~K}$ in MFI; this mixture is representative of that encountered in the petroleum industry and the IAST calculation results are shown in Fig. 8. Up to a pressure of $0.1 \mathrm{~Pa}$ the loadings follow the hierarchy dictated by the Henry coefficients; the higher the chain length, the higher the loading. It is therefore not possible to separate the linear from branched alkanes by operating at such low pressures. The situation changes dramatically when we consider the loadings at pressures exceeding $100 \mathrm{kPa}$ and total mixture loadings approaching $\Theta_{\text {mix }}=8$; under these conditions the sorption hierarchy is linear alkanes $\gg$ mono-methyl alkanes $\gg$ di-methyl alkanes. For example, at a total pressure of $100 \mathrm{kPa}$, the individual loadings are $n-\mathrm{C}_{5}=0.76, n-\mathrm{C}_{6}=$ $4.1, n-\mathrm{C}_{7}=2.6,2 \mathrm{MB}=0.032,2 \mathrm{MP}=0.02,2 \mathrm{MH}=$ $0.06,22 \mathrm{DMB}=0.00005,22 \mathrm{DMP}=0.004$ molecules per unit cell, indicating that the dimethyl alkanes are virtually excluded from the silicalite matrix. Configurational and size entropy effects overcome the hierarchy dictated by $\mathrm{C}$ numbers of the components in the mixture.

In order to confirm the predictions of the IAST we carried out CBMC simulations of the sorption isotherms of this 8-component mixture. The number of Monte Carlo cycles performed for each point on the isotherm was $1 \times 10^{9}$; the time taken to generate the entire isotherm was 8 weeks using one PC node $(500 \mathrm{MHz}$, Pentium III). The CBMC results are compared with the IAST predictions in Fig. 9. The CBMC simulations are in good agreement with the IAST predictions and confirm that it is possible to separate the 8-component mixture into three fractions consisting of linear, mono-branched and di-branched alkanes. For successful development of the separation technology, the $n-\mathrm{C}_{5} / 2 \mathrm{MH}$ and $2 \mathrm{MB} / 22 \mathrm{DMP}$ selectivities need to be significantly higher than unity. Selectivities exceeding about 5 are obtained provided we operate at near-saturation loadings $\Theta_{\text {mix }} \approx 8$. Operation at pressures exceeding $100 \mathrm{kPa}$ at $300 \mathrm{~K}$ will ensure this. It is interesting to 
(a) linear alkanes in 8-component mixture

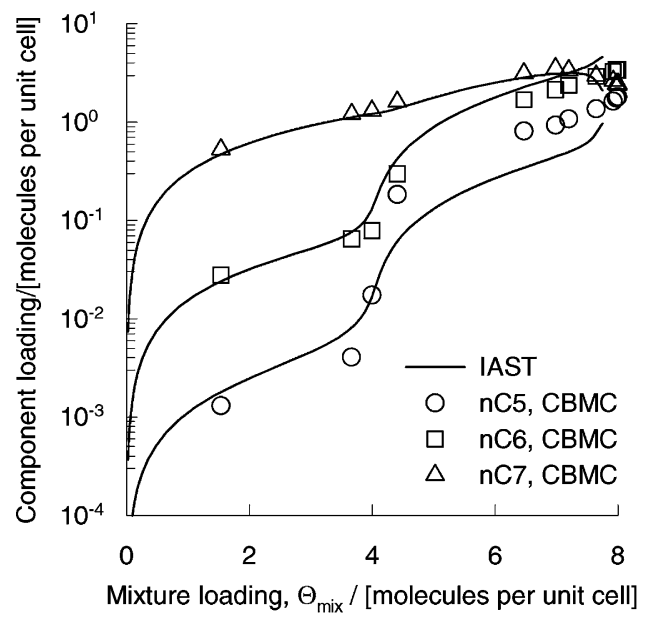

(b) 2-methyl alkanes in 8-component mixture

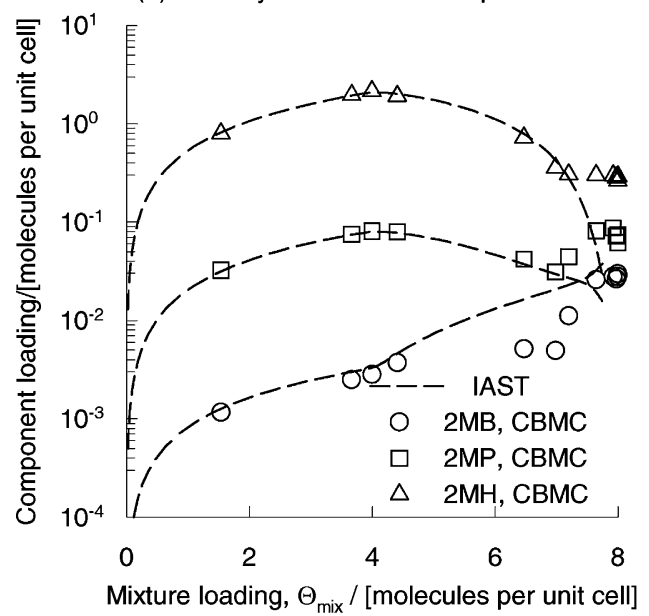

(c) Di-methyl alkanes in 8-component mixture

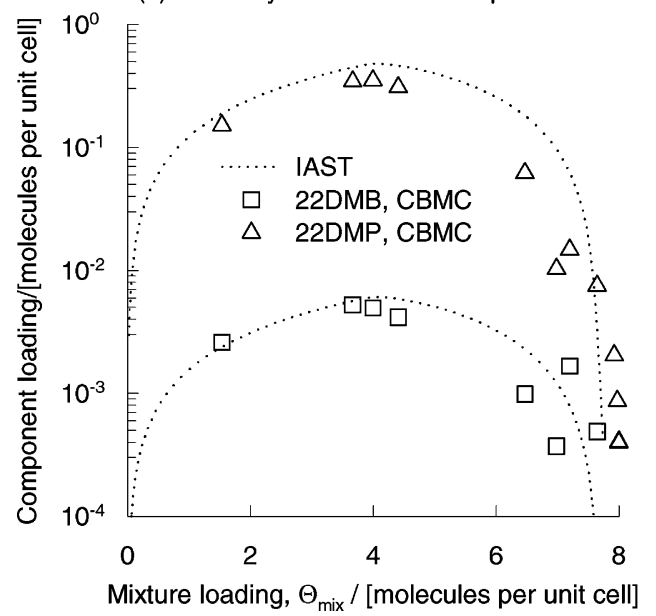

Fig. 9. Component loadings as a function of total mixture loading $\Theta_{\text {mix }}$ for equimolar 8-component mixture in MFI at $300 \mathrm{~K}$. (a) Linear alkanes, (b) 2-methyl alkanes and (c) di-methyl alkanes. Predictions of the IAST compared with CBMC simulations. note that the Henry selectivities are significantly lower than 0.01 .

The separation of the di-methyl alkanes from the 8-component alkane mixture is of considerable commercial interest and there is evidence in the patent literature [6,7] that the entropy principle is being exploited in commercial practice.

\section{Conclusions}

We have examined the sorption characteristics of various mixtures of alkanes, in the $1-7 \mathrm{C}$ atom range, at $300 \mathrm{~K}$ in MFI. The following major conclusions can be drawn:

1. For binary mixtures of linear alkanes in the $1-4 \mathrm{C}$ atom range, size entropy effects come into play at high mixture loadings and these counter chain length effects to reduce separation selectivities; see Figs. 3 and 4.

2. For binary mixtures of linear and mono-branched alkanes with the same number of carbon atoms, the sorption selectivity increases in favour of the linear isomer for mixture loadings $\Theta_{\text {mix }}>4$; see Fig. 5(a)-(c). This is due to configurational entropy effects. This effect is so strong that the mono-branched alkanes are virtually excluded from the MFI matrix at saturation loadings.

3. For binary mixtures of mono-branched and di-branched alkanes with the same number of carbon atoms, the sorption selectivity increases in favour of the mono-branched isomer for $\Theta_{\text {mix }}>4$; see Fig. 5(d). This is also due to configurational entropy effects.

4. For a mixture of linear alkanes in the $5-7 \mathrm{C}$ atom range the sorption hierarchy normally favours the molecule with the longer chain length. However, at saturation conditions $n$ - $\mathrm{C}_{7}$ suffers both size and configurational entropy effects; see Fig. 6(a).

5. For a ternary mixture of mono-branched alkanes, $2 \mathrm{MB}$, 2MP and $2 \mathrm{MH}$, configurational entropy affects the sorption loading of all three molecules when $\Theta_{\text {mix }}>4$. $2 \mathrm{MH}$ suffers the most and $2 \mathrm{MB}$ is the major benefactor; see Fig. 6(b).

6. From the quaternary simulation results presented in Fig. 7(a) and (b) we conclude that it is possible to separate linear alkanes from mono-branched alkanes with high selectivities provided we operate near-saturation loading conditions (i.e. $\Theta_{\text {mix }} \approx 8$ ).

7. From the quaternary simulation results presented in Fig. 7(c)-(e) we conclude that it is possible to separate mono-branched alkanes from di-branched alkanes with high selectivities provided we operate near-saturation loading conditions (i.e. $\Theta_{\text {mix }} \approx 8$ ).

8. From the 8-component simulation results presented in Figs. $8-10$ we conclude that it is possible to separate linear, mono-branched alkanes and di-branched alkanes from one other from a mixture of 5-7 C atoms with high selectivities provided we operate near-saturation loading conditions (i.e. $\Theta_{\text {mix }} \approx 8$ ). 


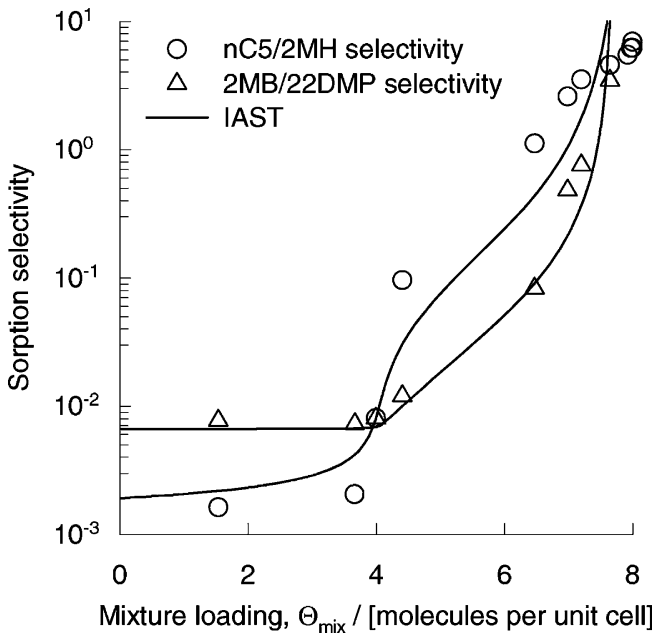

Fig. 10. $n-\mathrm{C}_{5} / 2 \mathrm{MH}$ and $2 \mathrm{MB} / 22 \mathrm{DMP}$ sorption selectivities as a function of total mixture loading $\Theta_{\text {mix }}$ for equimolar 8-component mixture in MFI. Predictions of the IAST compared with CBMC simulations.

Published literature provides evidence that the hexane isomers $n-\mathrm{C}_{6}, 3 \mathrm{MP}$ and 22DMB can be separated at high selectivities with MFI [33,34]. Our paper extends this concept and allows the development of a novel process for separation of linear, mono-branched and di-branched alkanes in the 5-7 C atom range using MFI. The main clue is to operate at high mixture loadings, approaching saturation (i.e. $\Theta_{\text {mix }} \approx 8$ ).

\section{Acknowledgements}

All the authors of this study have received grants from the Netherlands Organisation for Scientific Research (NWO), through the Netherlands Research Council for Chemical Sciences $(\mathrm{CW})$.

\section{References}

[1] D.M. Ruthven, Principles of Adsorption and Adsorption Processes, Wiley, New York, 1984.

[2] J. Kärger, D.M. Ruthven, Diffusion in Zeolites and Other Microporous Solids, Wiley, New York, 1992.

[3] D.M. Ruthven, S. Farooq, K.S. Knaebel, Pressure Swing Adsorption, VCH, New York, 1994.

[4] N.Y. Chen, T.F. Degnan, C.M. Smith, Molecular Transport and Reaction in Zeolites. Design and Application of Shape Selective Catalysts, VCH, New York, 1994.

[5] K. Huddersman, M. Klimczyk, Separation of branched hexane isomers using zeolite molecular sieves, AIChE J. 42 (1996) 405-408.

[6] R.S. Haizmann, F.M. Hibbs, S. Raghuram, Integrated isomerization and adsorption steps for upgrading C5 and C6 hydrocarbons, US 5043525 to UOP, Inc., 1993.

[7] H.W. Dandekar, G.A. Funk, H.A. Zinnen, Process for separating and recovering multimethyl-branched alkanes, US 6069289 to UOP, Inc., 2000.

[8] M.S. Sun, O. Talu, D.B. Shah, Adsorption equilibria of $\mathrm{C}_{5}-\mathrm{C}_{10}$ normal alkanes in silicalite crystals, J. Phys. Chem. 100 (1996) $17276-17280$.
[9] M.S. Sun, D.B. Shah, H.H. Xu, O. Talu, Adsorption equilibria of $\mathrm{C}_{1}-\mathrm{C}_{4}$ alkanes, $\mathrm{CO}_{2}$ and $\mathrm{SF}_{6}$ on silicalite, J. Phys. Chem. 102 (1998) $1466-1473$.

[10] C.L. Cavalcante Jr., D.M. Ruthven, Adsorption of branched and cyclic paraffins in silicalite. 1. Equilibrium, Ind. Eng. Chem. Res. 35 (1995) 177-184.

[11] L. Boulicaut, S. Brandani, D.M. Ruthven, Liquid phase sorption and diffusion of branched and cyclic hydrocarbons in silicalite, Micropor. Mesopor. Mat. 25 (1998) 81-93.

[12] W. Zhu, F. Kapteijn, J.A. Moulijn, Adsorption of light alkanes in silicalite. 1. Reconciliation of experimental data and molecular simulations, Phys. Chem. Chem. Phys. 2 (2000) 1989-1995.

[13] Z. Du, G. Manos, T.J.H. Vlugt, B. Smit, Molecular simulation of adsorption of short linear alkanes and their mixtures in silicalite, AIChE J. 44 (1998) 1756-1764.

[14] R. Krishna, B. Smit, T.J.H. Vlugt, Sorption-induced diffusionselective separation of hydrocarbon isomers using silicalite, J. Phys. Chem. A 102 (1998) 7727-7730.

[15] T.J.H. Vlugt, W. Zhu, F. Kapteijn, J.A. Moulijn, B. Smit, R. Krishna, Adsorption of linear and branched alkanes in the zeolite silicalite 1, J. Am. Chem. Soc. 120 (1998) 5599-5600.

[16] R. Krishna, B. Smit, T.J.H. Vlugt, Influence of isotherm inflection on diffusion in silicalite, Chem. Eng. Sci. 54 (1999) 17511757.

[17] T.J.H. Vlugt, M.G. Martin, J.I. Siepmann, B. Smit, R. Krishna, Improving the efficiency of the CBMC algorithm, Mol. Phys. 94 (1998) 727-733.

[18] R. Krishna, D. Paschek, Permeation of hexane isomers across ZSM-5 zeolite membranes, Ind. Eng. Chem. Res. 39 (2000) 2618 2622.

[19] R. Krishna, D. Paschek, Separation of hydrocarbon mixtures using zeolite membranes: a modelling approach combining molecular simulations with the Maxwell-Stefan theory, Sep. Purif. Technol. 21 (2000) 111-136.

[20] M. Schenk, S.L. Vidal, T.J.H. Vlugt, B. Smit, R. Krishna, Separation of alkane isomers by exploiting entropy effects during adsorption on silicalite. 1. A configurational-bias Monte Carlo simulation study, Langmuir 17 (2001) 1558-1570.

[21] T.J.H. Vlugt, R. Krishna, B. Smit, Molecular simulations of adsorption isotherms of linear and branched alkanes and their mixtures in silicalite, J. Phys. Chem. B 103 (1999) 1102-1118.

[22] R. Krishna, D. Paschek, Molecular simulations of adsorption and siting of light alkanes in silicalite 1, Phys. Chem. Chem. Phys. 3 (2001) 453-462.

[23] J.I. Siepmann, M.G. Martin, C.J. Mundy, M.L. Klein, Intermolecular potentials for branched alkanes and the vapor-liquid phase equilibria of $n$-heptane, 2-methylhexane, and 3-ethylpentane, Mol. Phys. 90 (1997) 687-693.

[24] A.G. Bezus, A.V. Kiselev, A.A. Lopatkin, P.Q. Du, Molecular statistical calculation of the thermodynamic adsorption characteristics of zeolites using the atom-atom approximation. Part 1. Adsorption of methane by zeolite sodium-X, J. Chem. Soc., Faraday Trans. II 74 (1978) 367-379.

[25] D. Frenkel, B. Smit, Understanding Molecular Simulations: From Algorithms to Applications, Academic Press, San Diego, 1996.

[26] B. Smit, T.L.M. Maesen, Commensurate "freezing" of alkanes in the channels of a zeolite, Nature 374 (1995) 42-44.

[27] A.L. Myers, J.M. Prausnitz, Thermodynamics of mixed gas adsorption, AIChE J. 11 (1965) 121-130.

[28] J. Van de Graaf, F. Kapteijn, J.A. Moulijn, Modeling permeation of binary mixtures through zeolite membranes, AIChE J. 45 (1999) 497-511.

[29] F. Kapteijn, J.A. Moulijn, R. Krishna, The generalized MaxwellStefan model for diffusion in zeolites: sorbate molecules with different saturation loadings, Chem. Eng. Sci. 55 (2000) 2923-2930.

[30] H.H. Funke, A.M. Argo, J.L. Falconer, R.M. Noble, Separation of cyclic, branched, and linear hydrocarbon mixtures through silicalite membranes, Ind. Eng. Chem. Res. 36 (1997) 137-143. 
[31] C.J. Gump, R.D. Noble, J.L. Falconer, Separation of hexane isomers through nonzeolite pores in ZSM-5 zeolite membranes, Ind. Eng. Chem. Res. 38 (1999) 2775-2781.

[32] T. Matsufuji, K. Watanable, N. Nishiyama, Y. Egashira, M. Matsukata, K. Ueyama, Separation of hexane isomers through an MFI membrane, Ind. Eng. Chem. Res. 39 (2000) 2434-2438.
[33] D.S. Santilli, Pore probe: a new technique for measuring the concentration of molecules inside porous materials at elevated temperatures, J. Catal. 99 (1986) 335-341.

[34] S. Calero, B. Smit, R. Krishna, Configurational entropy effects during sorption of hexane isomers in silicalite, J. Catal. 202 (2001) 395401. 